\title{
12
}

\section{NEW URBAN LANDSCAPES}

\section{Fragments of Civil Architecture}

\author{
Gino Malacarne
}

This contribution seeks to offer some theoretical reflections on the themes of the urban design and the reconstruction project of the European city, starting from some of the projects I have developed over time. The project research is oriented toward an architecture that can propose redevelopment/regeneration projects for marginal, peripheral, and abandoned urban places and is mainly oriented toward an architecture that can propose "new centralities for the suburbs."

These are places that have lost their urban role (once their original intended use was lost), or possibly they never even had one, and await important changes; this does not only concern urban suburbs but also areas that are often central in terms of location but marginal in importance within the city, lacking form and meaning. Last, the research focuses on places awaiting substantial transformations, in search of new uses and new formal identities.

Our task should be to propose a form for these city places.

As for urban suburbs, which largely characterize the face of the contemporary city, they also represent the largest part of the urban heritage that must be redeveloped. The "new city," an expanse of residences-dormitories, has not yet found an independent life and has lost its initial vitality.

As has been observed (Monestiroli 2009, 172-181), ${ }^{1}$ the "suburbs are a large, completely privatized territory (...) a place devoid of the fundamental requirement of every city, which is the relationship between public and private." It therefore becomes necessary for any redevelopment project to favor a new relationship between collective places and residential areas. This means proposing, at least for large and medium-sized cities, a polycentric model of the city.

Urban suburbs are essentially an economic and social problem, but the architectural project can greatly contribute, giving shape to the urban shapeless. And even if we would like to see social and spatial appropriation strategies, "practices," and "tactics" (De Certeau 2012, 69-75), ${ }^{2}$ these alone, albeit necessary because they nurture a sense of belonging, will not be enough. Only architecture can build the conditions (places) for the development of a dignified urban life. As Henri Lefebvre wrote, "Urban life, urban society, in a word 'the urban' cannot do without a sensitive practical base, of morphology" (Lefebvre 1970, 65-68). According to Lefebvre, the city 
is a work similar to a work of art rather than a mere material product. (...) Nothing works without a regulated succession of acts and actions, decisions and behaviors, without messages and without codes. Nor does it work without things, without a material to model, without a practical-sensitive reality, without a site, a "nature," a countryside and surroundings.

This project research therefore aims to develop around an idea of "new city," the urban suburbs (and in general all peripheral and marginal areas), and the city of our times to which no one has yet offered adequate answers in general terms. It aims to propose an architecture grafted and superimposed on the existing city not only to design and incorporate changes/ corrections but also to intervene in order to provide contrasts in the urban landscape, thus giving new meanings overall to the city space.

The themes of redevelopment and transformation of entire urban areas become concrete opportunities to respond to the issues of the quality of urban space and the expectations hitherto hidden or eluded by the great urban expansions. A reflection is therefore necessary to concretely evaluate the questions of the urban form inscribed in the centrality of the architectural design.

The conformation of current cities, their urban and territorial structure, are in fact, as we know, the result of urban planning that has mainly concerned itself with managing and guiding urban growth over the years. This organizational need became essential in the attempt to manage the extraordinary urban development, faced with the immeasurable territorial development and the consequent enormous urban growth that has affected cities especially since the Second World War.

From the art of building cities we have passed, almost progressively, to tasks dictated by other disciplines, but, as Hans Schmidt observed, "The men who form a society do not only need a technique but also an urban art, the meaning of which consists in expressing all the multiplicity of social relations with the means of spatial configuration."

In general, we can say that our current cities are the result of an idea and a planning that have replaced, over time, the natural ideal drive that every development aspiration contains, a construction praxis increasingly linked to contingencies and functional specialization (traffic, residence, services, production, greenery, the historic center, the tertiary sector, etc.) producing, in fact, a fragmentation unable to restore a general formal sense to an urban planning program.

The plans' current structure is based above all on a descriptive abstraction of reality that relies almost exclusively on the potential of numerical calculation and on regulatory directives based on indices, ratios, and standards. In this process emerges an abstract, diagrammatic interpretation of the city that reduces and eliminates the richness of the physical and figurative materiality of the city and the territory, to the point of making it unrecognizable and inconsistent. "A diagram is abstract. Cities, however, are concrete. Cities, like individuals, have their own physiognomy" (Hilberseimer 1967, 31).

It therefore seems desirable to link the research and definition of urban places to the necessary urban framework. A link that is now more necessary than ever in order to give the city and its places back not only a material and economic meaning but also a spiritual one linked to the 
shape of the city, its history, and its memory, which overcomes the abstract filter of technicalnormative instruments, opening up a reflection on the destiny of the city and its architecture.

Within this general framework, the issue of defining the urban form naturally represents a possibility for the city, but it should be recalled that it defines only one aspect of a complex framework in which issues, techniques, and economic strategies converge, all concerned with governing the vital dynamics and use of the city.

Nevertheless, for those who "believe" in the architecture of the city in which to find and prefigure a system of order made up of hierarchies, fixed scenes, and recognizable configurations, the theme of urban form is an equally important and central fact of identification of the urban areas' functional aspects.

When discussing the importance of form, I fondly recall Adolf Behne.

Nothing is more understandable than the fact that the rationalist gives particular emphasis to form: this in fact arises with the establishment of human relationships. The lonely individual, isolated in the middle of nature, has no problem of form. Man alone, even if he is alone in Nature, is free. The problem of form arises together with that of the union of several individuals, indeed form is the condition that makes coexistence possible. Form is an eminently societal fact. Whoever accepts the laws of society also accepts those of form.

(Behne 1968, 58)

It is undoubtedly a matter of favoring, through the definition of form, urban processes that are an alternative to the mere urban practice of standards, therefore capable of recalling, even if only in significant fragments or parts, the themes of urban centrality, the value and wealth of the overall form of the city, and, why not, the identity of the places.

The task of the urban project should therefore be to re-propose the reasons for the form of the city, those underlying and complementary to the re-appropriation of its value, its meanings, and its beauty, as well as its desirable and correct functioning.

Its role must be inscribed within this order of things as a search for this double soul of the city; a material one, the expression of the city structure and layout, the other cultural elements or features, visible in those forms of theoretical, artistic, or literary representation, and, more generally, in that set of representations, images, and ideas forged over time and generative of the multifaceted universe that is the city.

The need for a different attitude toward urban reality is also the result of a different way of understanding territorial resources. In the recent past, a territory was intended as an inexhaustible resource of productive, residential, and agricultural exploitation, a connotation that today, after the great phase of uncontrolled urban expansion, "could" connect to issues increasingly linked to attitudes of redevelopment, of transformations of areas considered resources to be protected in the context of a revival of expectations and constructive responses to be developed for the construction of our cities.

The humanistic core of the rebirth of the urban design and its ability to relate the needs of reality with research and the beauty of sensible forms lie in this "recovery" of an urban thinking that becomes project, "knowledge," and the ability to interpret reality.

A thinking capable of "understanding" the different aspects of reality - political, economic, technical, and poetic - and channeling them into a constellation of similar images that reverberate from the territorial scale to that of the single part of the city. 
In this way, the territory, the natural environment, and the built environment are placed and interpreted as a whole in the urban design and are no longer considered separately in their changing exchange of values and relationships together with the whole framework of urban forecasts.

\section{2}

The projects I present envisage a "rebirth" for parts of the city that are "lacking and needy."

The projects propose the construction of places that seek to be significant and which (in going beyond the contingent problems that the areas present) aspire to become new urban centralities, points of reference, and cornerstones in the suburbs of the cities of our time in areas where the urban form is being lost.

In the city understood as an artifact, the "plan" is implemented with architecture, the only possibility for an urban project that contemplates a significant form of the city, with its own character, as a final result.

The projects are then built as pieces of analogous cities that are rooted in the built city and the imaginary to which they refer. The ability to imagine figures and spaces derives from knowledge of historical cities (from the urban facts that characterize cities). In fact, the city is a place of common values and a "theater" where human events take place; it is the custodian of a tradition of urban forms forged by time and the life of men. I therefore share the projects and ideas of cities that refer to known places that are transcribed, reinvented, and rediscovered in the project, noting with Cesare Pavese that true amazement is made of memory and not of novelty.

Through urban analysis, the reference to types and figures deriving from history also contributes to making the urban facts recognizable and identifiable. The projects establish a relationship with history to be understood as generative, not as imitation, and which is built through an analogical process.

As happens in the best architecture, it is the "precedents" and the historical references that can be glimpsed therein which feed the imagination that they themselves produce. Indeed, evocative images are necessary for the principle of recognition and identity construction of places.

The architecture of the city is the urban theater of civil life or, according to Aldo Rossi, the steady scene of human affairs; urban scenic space is therefore an essential component of the urban design and is a figure that recurs in my work as an architect. This component requires careful work on the implementation and representation of the project; in fact, if the city is the theater of public life, it is the architecture, through its facades, that makes the urban landscape intelligible in terms of culture and experience.

\section{Duisburg}

The project for Westhafen in Duisburg concerns a heterogeneous area located on the edge of a small urban center on the outskirts of the city, characterized by some of the basins of the large river port of significant disuse. The project area is a peninsula located between two port basins in search of new functions, new uses, and new formal identities. The intervention in shaping the place through architecture goes beyond the contingent problems that the area presents and proposes a fragment of civil architecture in an area where the shape of the city is being lost (Figure 12.1). 


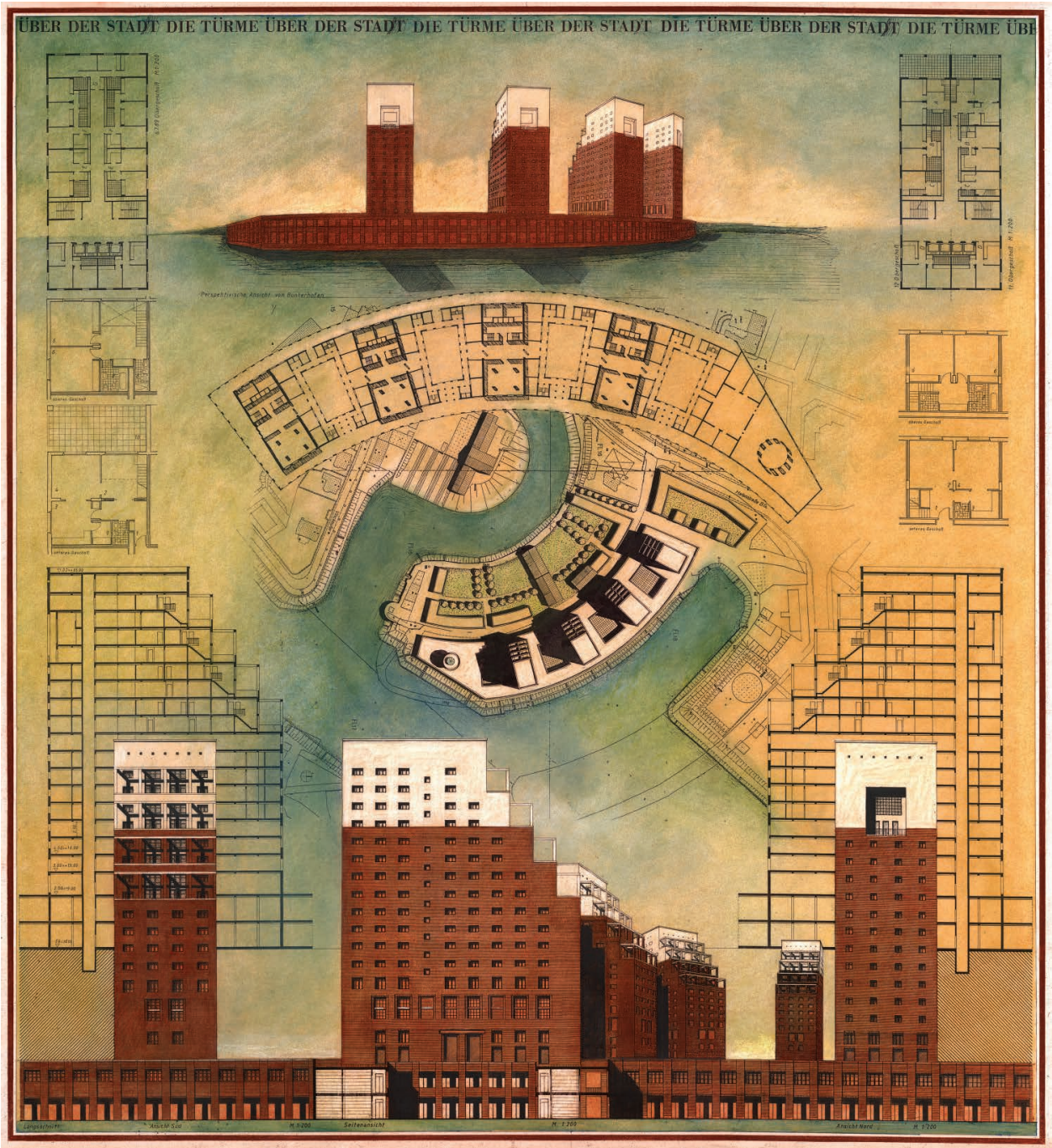

FIGURE 12.1 Gino Malacarne, Project for the Werfthafen of Duisburg, 1989/1990.

The project, which involves the construction of an articulated and complex settlement unit intended for different functions, also becomes the occasion for complex typological experimentation and involves a type of tower on a base (a type of residential building in which the residence is inextricably combined with some related services). The large base adapts to the morphology of the peninsula and alternates a sequence of towers in succession interspersed with courtyards that identify the public spaces. The base and the towers simultaneously confront the nearest urban dimension and the landscape of the industrial city, the port, and the city in general and act as a cornerstone.

The project therefore reveals its urban calling, as it is built in parts that structure different relationships with the city and at the same time presents itself as a unitary architecture, a large completed factory, and a new part of the city. 


\section{Berlin}

The project for the "Königsstadt" area of Berlin includes the part of the city characterized by the crossing of the stretch of Karl Marx Alle rebuilt starting in the 1960s that goes from Alexanderplatz to Strausberger Platz. Here, the destruction from the war, then the systematic demolition of the historic city that remained standing, and the abolition of landed properties made it possible to plan the functional city, in the particular sense of the GDR experiment of a socialist city. It had to become a part of an egalitarian city that would have eliminated differences and hierarchies through the application of functional specialization criteria derived from socioeconomic disciplines: no longer city center, or suburbs, but equal living conditions for all. The unsuccessful attempt to build a new urban life is today revealed merely as a large suburb (a central area in terms of location but peripheral in form and content) even if it is "of equality." This architecture "restricts the concept of living to living in a specialized way" (Figure 12.2).

Recognizing that the "course of history is irreversible" and that it is not possible to try to reconstruct what has been demolished, the project seeks to build a new urban identity for this part of the city through a process of densification and stratification of pieces and new parts that create new spatial configurations.

In some cases, the project strengthens, and in others invents, urban purposes; it is essentially an operation of "completing" what exists, even if in the light of a new idea of the city.

The design project took shape starting from the redefinition of the streets and their renewed urban propensity. The stretch of Karl Marx Allee crossing the area becomes the center of the intervention and the project accentuates the monumental calling of this urban axis, ideally reconnecting with the idea of a large modern urban road previously created by Henselmann. Buildings in line, arranged parallel to the existing buildings, marked by vertical elements, give a rhythm to the street together with towers that also provide views and close visual axes; they are the architectural elements that substantiate the urban design. The new buildings in line also narrow the road axis, and, with the existing buildings, form measured sequences of public pedestrian spaces parallel to this road.

\section{Cracow}

The project for the southern area of Cracow (within the general urban design: Seven Gates to Cracow) proposes a clear and recognizable shape for the southern border of the city, characterized by the urban highway leading to Zakopane, interpreting the architectural theme of the "city gate" and the urban limit and how this theme can be understood at the beginning of the third millennium (Figure 12.3).

The design project expresses the more general desire to build an urban fragment with its own autonomy and completeness, a sort of sign capable of connoting and inserting itself within a system of triangulations with other figures and architectures of the urban landscape.

The proposal is a new "standing city" immersed in nature in the countryside and includes a sequence of towers arranged on a base that delimits large open spaces, proposing an "open spatiality" and embodying the idea of a "city arranged in nature."

The intervention is built starting from the base, an elongated parallelepiped arranged in an east-west direction and marked by a succession of open courtyards alternating with the towers. There are seven towers on the base, cut and interrupted by the highway with three 

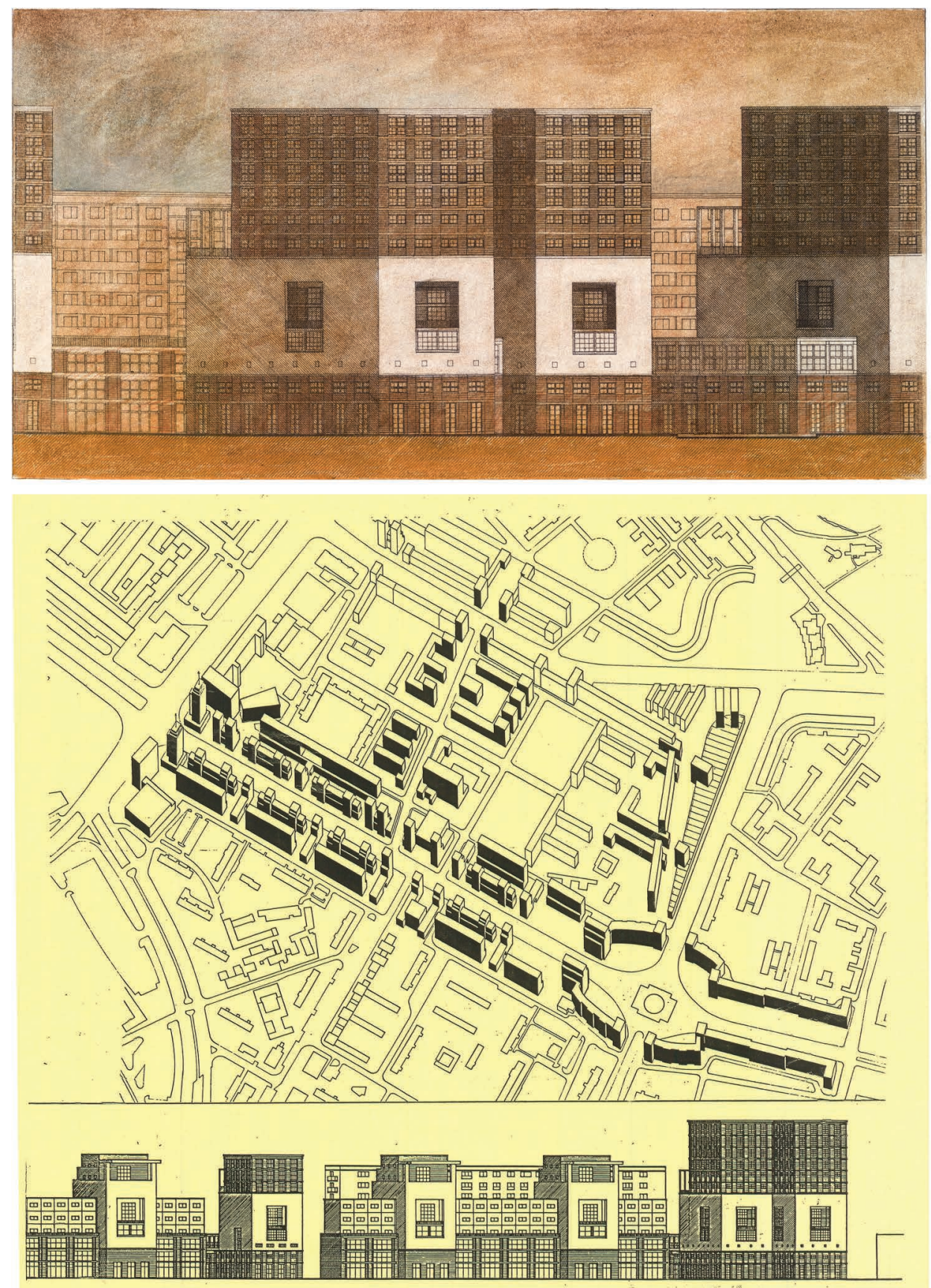

FIGURE 12.2 Gino Malacarne, Project for Berlin Konigsstadt, Berlin, 1995. 

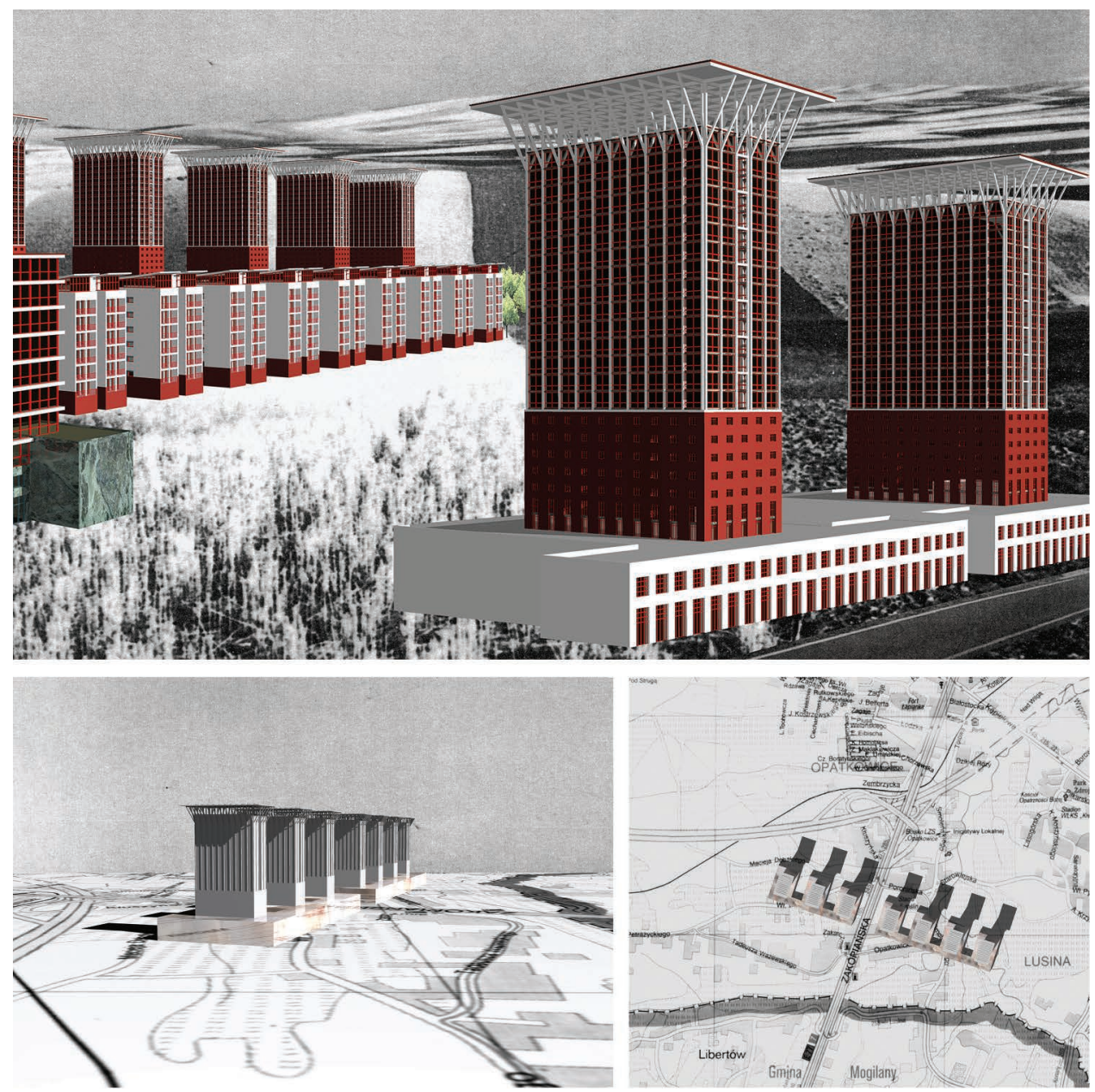

FIGURE 12.3 Gino Malacarne, Zakopane Gate, Project for the southern area of Krakow (Seven Gates to Cracow), Krakow, 2000.

to the west and four to the east, as if to underline the unfinished nature of the intervention and suggest the possibility of future urban developments.

The base and towers stand out as clear-cut volumes whose arrangement evokes the layout and clarity of a founding city. The towers accept the relationship of scale with the landscape and with the parts of the city more generally, thus favoring a wider system of relationships.

\section{Modena}

In the redevelopment project of the vast urban area of south Modena, in which urban forms are gradually disappearing, atomizing themselves in the indistinct flow of peripheral expansion, an attempt is made to demonstrate how a general framework of transformation can be prefigured without proposing any tabula rasa or attempting to unify something that clearly cannot be unitary (Figure 12.4). 


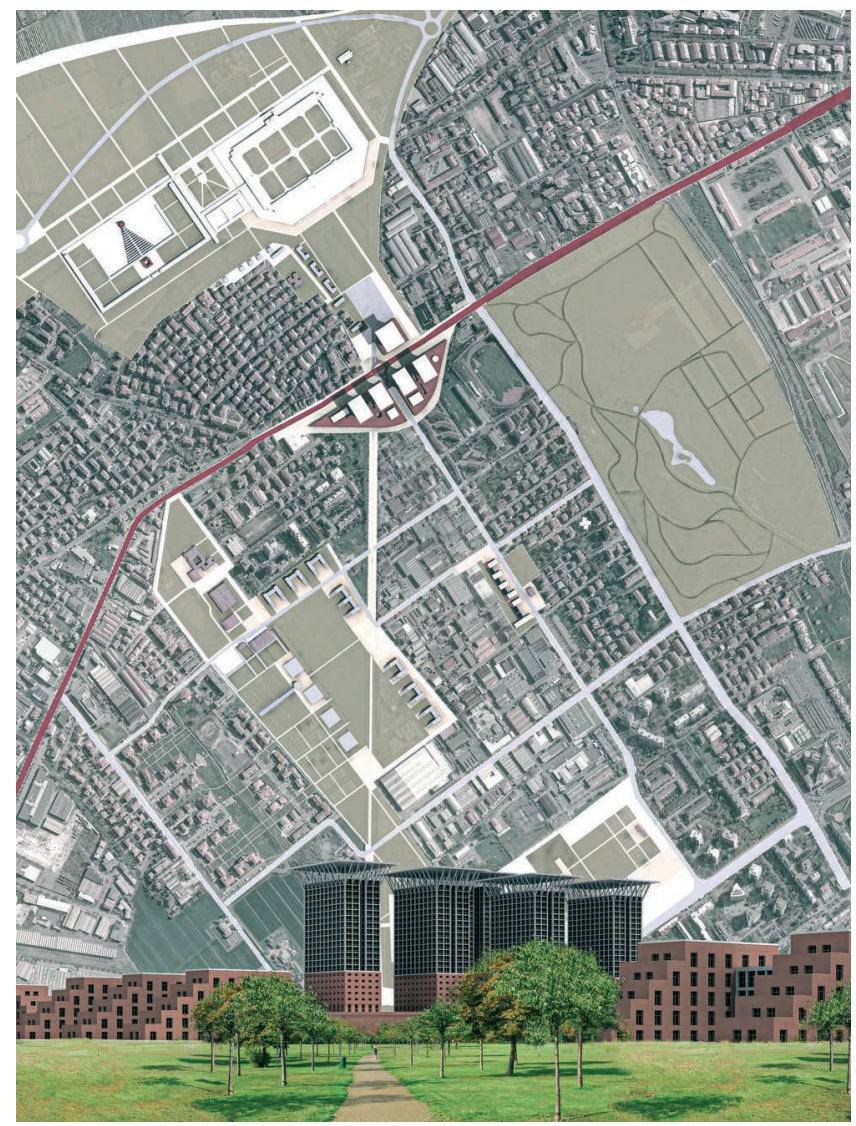

FIGURE 12.4 Gino Malacarne, Urban Redevelopment Project (for the Artisan Village and the Madonnina District), Modena, 2005.

The project addresses a complex area affected by an urban transformation process triggered by the displacement of the railway line. The general configuration of the design project reveals a dialectical tension between the existing areas and design areas that highlights the intention to regenerate these areas, now separated from each other, transforming them into real urban places recognizable as such and related to the broader framework of infrastructures and centrality of the city.

The project therefore addresses the question of the city's architecture and its construction; this primarily concerns the identification of urban themes that the project articulates as parts of a more general design in which each of them plays a specific role in the aspiration to a discreet urban unit.

The intervention identifies and develops three distinct urban parts connected by a long urban axis and other road axes - whose figurative qualities are expected to be strengthened which seek to reconnect the entire area and the city.

Three major compositional themes characterize the three parts: the "turreted citadel," the "civic forum" (a large greenfield surrounded by new architecture), and the "memory park," which includes the cemetery, the large greenspace, and the countryside surrounding it. 
Five towers on a base constitute the hub of a wider and more complex urban reconfiguration, which is identified with the grounds of the viaduct being decommissioned. This "turreted citadel" makes the stretch of Via Emilia "forgotten" and "cut" by the construction of the old railway line, the center of the project. From the south, in particular along the axis that leads to Via Emilia, and in general from all directions, the towers will clearly define the new fixed scene of the city before the new areas affected by the project and the overall scale of the city of Modena, offering an image for the future.

\section{Verona}

The project for two residential blocks in Verona is located in an area on the southern edge of the city behind the railway yard, where the city's industrial development was concentrated during the mid-20th century (activity now discontinued) and the Fairgrounds (Figure 12.5).

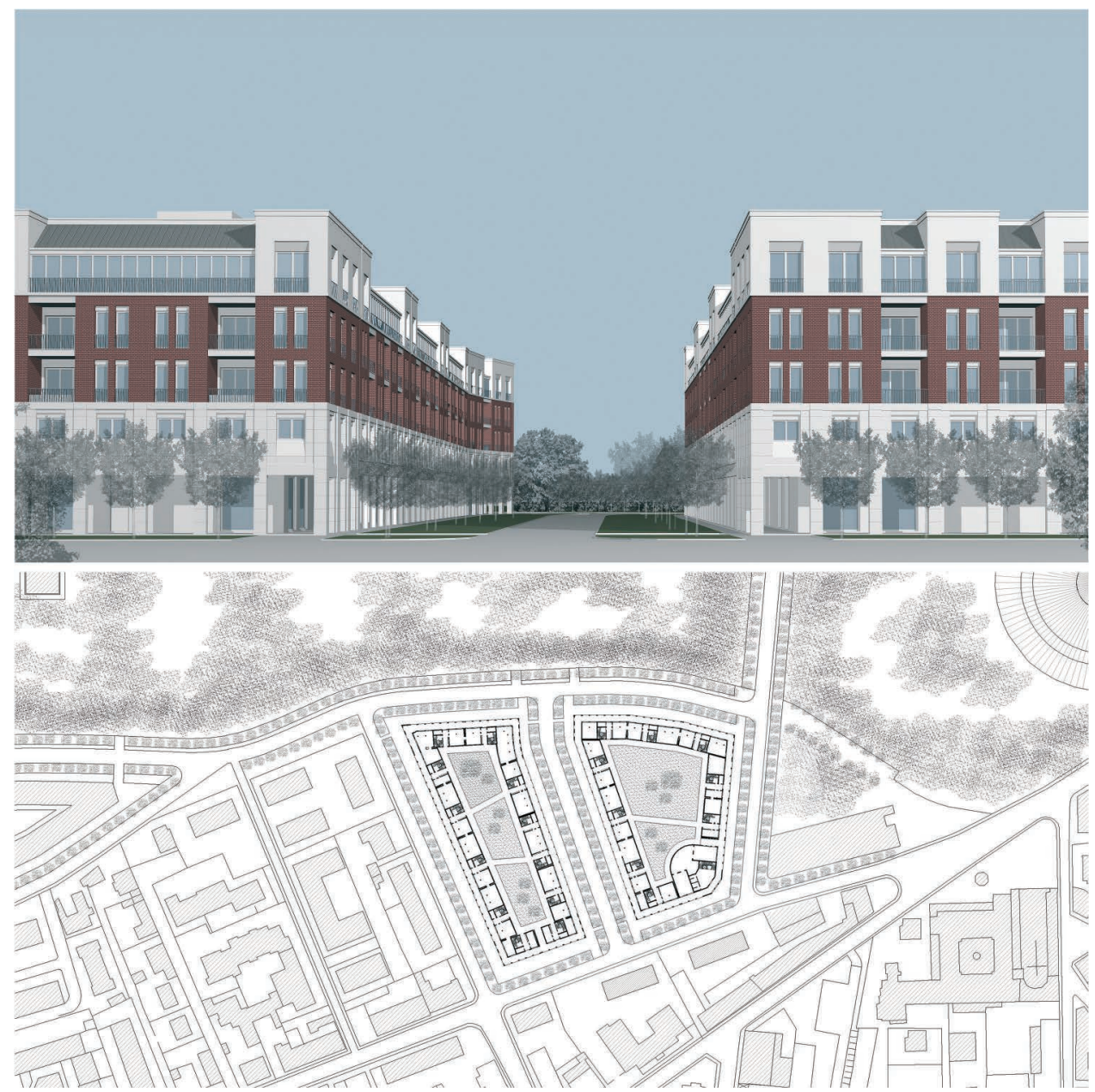

FIGURE 12.5 Gino Malacarne, Two residential blocks project, Verona, 2007. 


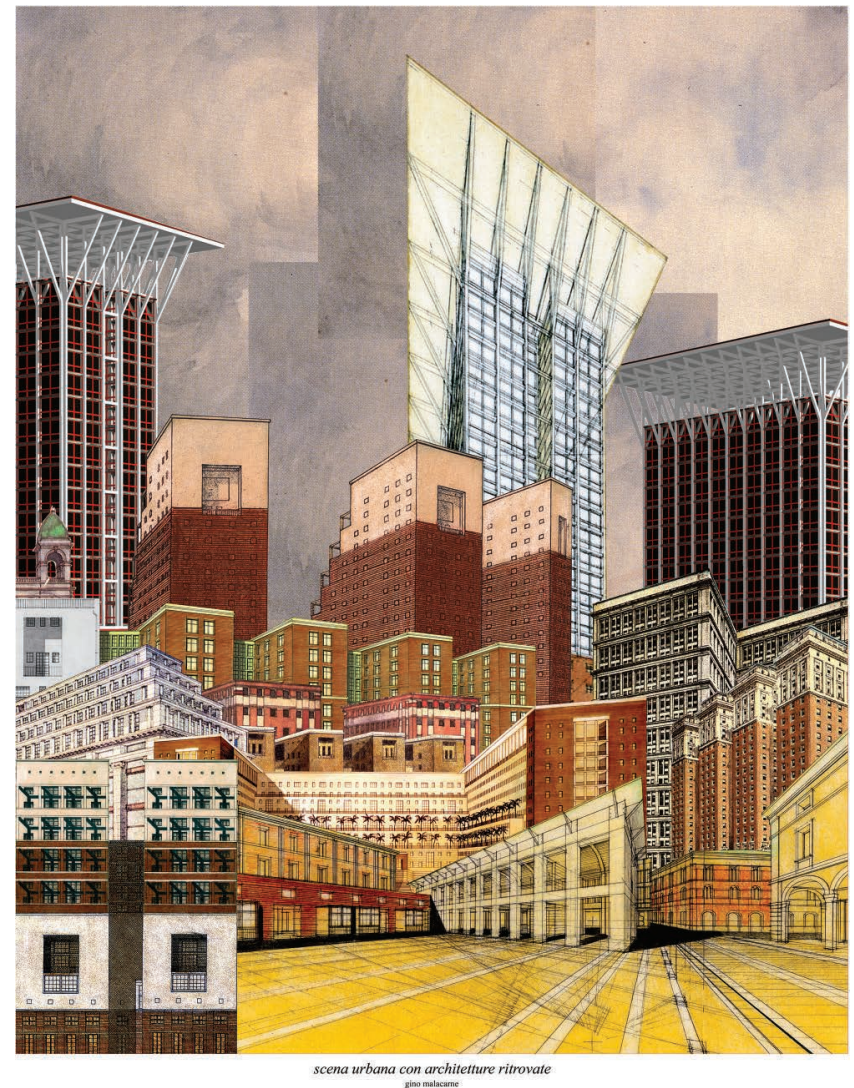

FIGURE 12.6 Gino Malacarne, Scena urbana con architetture ritrovate (Urban scene with rediscovered architecture), 2020.

The redevelopment project welcomes and shares the constraints of the envisaged urban program but leads them back to a broader reasoning of architecture, seeking a system of correspondences and analogies with the ancient city. The two blocks of the project show, relative to the discontinuity and fragility of the surrounding building fabric, the strength of a unitary principle, looking to Verona and its tradition as a living example, a possible alternative.

The relationship with the street is resolved by a continuous arcade on the ground floor that surrounds both blocks and builds a system of urban hierarchies. The arcade links the building to the road network and leads to the large garden courtyards in the center of both blocks. But the arcade also becomes an opportunity to underline the different role of the streets and of their being again: not just a road axis, but a public, collective space. A collective space also characterized by an idea of an architectural ensemble that defines the face of this part of the city. Architecture thus becomes the fixed scene of the collective space.

The architecture of the building represents the compositional and distributive logic that overlaps the different functions envisaged in the building in height, showing it as a matter of architecture, transposing it into an organizational principle of the volume and the facade 
through the superimposition of horizontal bands. It perhaps reflects the facades and the organizational logic of the historic buildings in Verona by orders.

In an elongated view, the buildings face the large greenspace and are entirely revealed in the organization of horizontal bands, in the ordered architecture, its belonging to the city, and its civil character, like a large urban scene that concludes the city and opens toward the park.

The projects indicate possible ways of promoting an urban process that does not exist today and a "social life which architecture can only encourage but certainly not determine" (Figure 12.6).

\section{Notes}

1 Some considerations are taken from the essay by Antonio Monestiroli (2009, 172-181).

2 Some of the themes were enunciated by Michel de Certeau (1990, 2012, 69-75).

\section{Bibliography}

Behne, A., L'architettura funzionale (original title Die Moderne Zweckbau, 1923). Firenze: Vallecchi.

De Certeau, M. 2012. L'invenzione del quotidiano (original title L'Invention du quotidien, are taken up again, Paris 1990). Rome: Edizioni Lavoro.

Hilberseimer, L. 1967. L'idea di Piano. Venice: Marsilio Editori.

Lefebvre, H. 1970. Il diritto alla città. Venice: Marsilio Editori.

Monestiroli, A. 2009. Neue urbane Plätze/New urban squares. In Die Idee der Stadt/The Idea of the City. Tübingen-Berlin: Wasmuth, (vol. I/III). 